\title{
Research on Computer-assisted English Teaching
}

\author{
Rui Han ${ }^{1}$, Yanlin Yin ${ }^{1}$ \\ ${ }^{1}$ Heilongjiang University of Technology, Jixi, Heilongjiang, 158100
}

Keywords: computer-assisted technology; teaching research; student cooperation

\begin{abstract}
The introduction of multimedia devices into the classroom is a great change in the form of education, and it has already occupied the classroom in a strong way, bringing us an improvement in the quality of education and the optimization of teaching models. At the same time, it quietly has had some influence on English teaching. This paper discusses the significance and advantages of computers entering the classroom based on the characteristics of English teaching, and discusses the influence of professors' misuse of computer-assisted devices on English teaching and the strategies for solving them.
\end{abstract}

\section{Introduction}

Today's internationally popular constructivist learning theory emphasizes the important role of "scenarios" in meaning construction. Computers solve the problem of context creation. In the process of teaching, multimedia teaching software is used to create English teaching, listening and speaking environments, through concentration. The screen provides a variety of scenes, such as the recurrence of historical images, the display of daily customs, special celebrations, etc., can be achieved through computer simulation. All of these can help students understand and master the language, and ultimately achieve the purpose of communicating independently with verbal communication. Back-to-back words, grammar, sentence patterns, and copying texts cannot really learn the language! Scene simulation enriches the teaching content, strengthens the teaching effect, and stimulates the learning atmosphere. Moreover, as a result of the combination of visual and speaking, it has increased students' perception and memory of language and created an environment similar to mother tongue learning, which has achieved good results. The use of multimedia teaching software enables students to advance along the path from vivid intuition to abstract thinking, and fully mobilizes students' intellectual and non-intellectual factors to participate in awareness activities, enhance the motivation and ability of understanding, and shorten the The time of understanding and mastering the learned knowledge accelerates the understanding process and improves the learning efficiency and quality. In such a strong atmosphere, learning a language is no longer a boring job. On the contrary, because of the change in teaching methods, the burden on students' learning has been reduced a lot. Through the use of Internet resources for language teaching, students have not only continuously improved their listening and speaking skills, but also cultivated students' abilities to engage in active learning, self-study, and cooperative inquiry, and further developed the ability of students to summarize, summarize, and comprehensively use language communication. The study results have been significantly improved, so that each student's initiative has been played, learning confidence has greatly increased, but also truly reflects the learning and learning.

Cognitive psychology studies show that $94 \%$ of human life is obtained through visual and auditory information. Of these, $88 \%$ were visual and $12 \%$ were auditory. This shows that the visual organs are the most important human organs. When students learn the same materials, they can use both sight and hearing at the same time, which is much more effective than using auditory learning alone. The multimedia computer provides students with comprehensive stimulation of multiple senses, resulting in a rich variety of human-computer communication. It not only changes the traditional teaching mode, but also enables sounds and images to be transmitted, stored, extracted or presented in a very short time in a large number of languages, pictures and animations. "Learning a foreign language without understanding its culture is tantamount to remembering a series of 
symbols that have no practical significance." It is difficult to use effectively, and it is often misplaced in times of inappropriate use. Sometimes it even makes you laugh. Classroom is the main place for foreign language learning. With multimedia-assisted teaching, the amount of information in the classroom is not limited to limited textbooks. If you can connect to the Internet, you can achieve information sharing around the world, bring students to the world, and bring the world to you. student. At the same time, it can visualize and concretize cultural and social factors such as social and cultural backgrounds in the form of text, images, sounds, and videos, which is conducive to the construction of students' cognitive schemas. Due to the multiple stimuli of sounds, images, and texts, teachers and students can sing their voices, view their forms, and immerse themselves in the environment. They are completely immersed in the atmosphere of teaching requirements and receive teaching effects that cannot be matched by other teaching methods. Teachers do a good job in the introduction, presentation, operation, free communication, and summarization of classroom teaching to fully utilize the multimedia functions of images, videos, prompts, and background music, and deliver a lot of vivid, intuitive, scientific, and accurate information. Information, expand classroom capacity, enrich teaching content, and improve teaching efficiency.

\section{The Impact of Computer-assisted English Teaching}

Whether or not computer aided devices are used in teaching has become the most significant indicator of modern education. Especially in English teaching, the configuration of high-definition projectors has made it possible to quickly solve many obscure problems in classroom teaching. However, due to the rapid popularity of computer-assisted English teaching models, many teachers are caught off guard. Therefore, in practical teaching, the use of computer-assisted devices is limited to the functions of tape recorders and projectors. Next, the author wants to discuss the influence of the abuse of computer-assisted devices by the lecturers and their influence on English teaching [1].

Computer-aided teaching began in the late 1950s, and its popularity in China began in the mid-1990s. The author took 200 learners as samples and conducted a survey of the instructors' use of computer teaching in English classes. The data showed that $93.8 \%$ of the lecturers used slides and projectors in class, and over $75 \%$ of them were The lecturer repeats the content of the PPT for 30 to 45 minutes during class. The data tells us that at present, more and more teachers are proficient in combining computer-assisted devices with their own teaching, but the trend of dependence on computer-assisted devices is becoming more and more obvious. As far as English teaching is concerned, it is a kind of cultural education. The use of computers for teaching is originally an aid, but it has gradually become the main means of teaching the lecturers. The same version of the teaching courseware can be used together by a teaching and research group. A lecturer can also use it to teach several classes at the same time. The lecturer was completely left by the PPT! Using the same teaching courseware will not only affect the lecturer's teaching style and thinking, but also restrict the exertion of the subjective initiative of the lecturer. At the same time, the production of this PPT also helps the lazy penalties. For learners, it is true that computers have increased the interest of learners to a certain extent, but at the same time they have also contributed to the learners' utilitarianism. Taking the review of the final exam as an example, the author conducted a survey of the review methods of the final exam for a class of 32 students. The data shows that only $11.58 \%$ of students believe that they only fail to watch the courseware. This precisely reflects the degeneration of the teacher's initiative to a certain extent. It seems that computers help students to achieve "no self-discipline", but in fact both the lecturer and the learner have reduced the higher requirements for education [2].

Because of its huge capacity and high transmission efficiency, it is a characteristic of computer equipment itself. Therefore, in actual teaching, the lecturer fully utilizes and exerts this advantage. Taking a projector as an example, not only can the lecturer's time for writing a book be saved, but also the page-turning speed can be increased without limitation. Therefore, in English teaching, like the teaching of other courses, the lecturer also pursues a large amount of information, ignoring the control of the classroom rhythm, and ignoring the learners' ability to accept and understand. The 
teaching under computer aided equipment has become a kind of (in my opinion) new "indoctrination" teaching method. In particular, English classroom instruction is used as an example. Large paragraphs of text appear on PPT, and the rate at which the lecturer reads the text is generally faster, causing the learner to take classes and appear unresponsive.

\section{Strategies and Recommendations of Computer-assisted English Teaching}

The application of computer in teaching has given fresh blood to English teaching, which has greatly improved the efficiency of classroom teaching and paved the way for educational innovation. But in the final analysis, computer teaching is only a supplementary teaching method that can help students better understand and master the teaching content. The key to the problem is whether teachers can properly use computer-aided teaching equipment. Only by combining computer-assisted instruction with English teaching science can we allow computer-aided equipment to maximize its efficiency and minimize its negative impact. Combining the advantages and disadvantages of computer teaching in English teaching, the author puts forward the following teaching suggestions: First, teachers should play an active and leading role in this reform, and strive to let themselves into the revolution of this new technology. The lecturer is still the subject of the "learner-centered" teaching model in the transmission of knowledge. In English teaching, it is necessary to avoid the "obtrusion of masters" of multimedia devices, reduce excessive dependence on computers, PPT, and use whiteboards [3]. The display, which combines traditional and modern teaching methods, allows learners to pay more attention to the speaker's interpretation of the language while using audio and video to help the learner understand the instructor's instructions and difficult information [4]. Second, given the excessive reliance of learners on multimedia teaching tools such as electronic courseware before the exam, the lecturer should encourage learners to participate in classroom and extracurricular language practice activities, and to exercise the learner's ability to actually use the language instead of a single language. Test ability. At the same time, the lecturer can use computer-aided teaching equipment to create more realistic language environments for learners, such as searching for exotic partners through the Internet platform [5]. In addition, the lecturer should minimize unnecessary visual impact in the classroom and enable the learner to focus on the content to be mastered. The lecturer should actively ask the learner to learn the effect and degree of acceptance, adjust the instructional rhythm at any time, and focus on the difficult points of explanation, focusing on the high quality of classroom teaching effects. At the same time, the lecturer should respect the cognitive laws of learners. In terms of listening and speaking training, they should respect the principle of "listening before hearing" and scientifically improve the English literacy and level of learners. Multimedia computer technology embodies the two characteristics of interactivity and individualization. Interaction is conducive to inspire students' interest in learning, so that students have a strong desire to learn and form the motivation of learning; Multimedia computer provides an interactive teaching environment, the so-called interactivity, that is, students learn not only passively, but can learn passively. Participate in the process. Traditional teaching process is almost everything dominated by the teacher. From the teaching content, strategies, methods, steps, and even the students' exercises are all arranged in advance by the teacher. Students are only passively involved. In the multimedia interactive teaching activities, the computer can quickly respond to questions raised by the students, make logical judgments on answers provided by the students, and provide feedback to the students in a timely manner. In this way, the students make full use of the computer to practice and exercise the comprehensive ability of English. In this learning environment, students can choose the learning content according to their own learning foundation and interests. This interactive learning mode provides an ideal environment for students to actively participate.

\section{Conclusion}

We have entered the era of big data. Although each of us enjoys the benefits of computer-assisted teaching, we cannot ignore its negative effects. Based on the affirmation and expectation of the role 
of computer equipment in English teaching, the author hopes to use computer-aided teaching equipment to improve the learners' ability to speak and speak in English more quickly.

\section{Acknowledgements}

Jixi Social Science Research Project (Key Project), Project Number: 2017JSK011

\section{References}

[1] Chen Jianlin. From Assistant to Dominant --- The New Trend of Computer Foreign Language Teaching Development [J]. Electronic Language Teaching, 2005 (4)

[2] Li Deyu. Promote learning reflection and improve learning efficiency [J]. Contemporary Education Forum, 2009 (5)

[3] Wang Shouheng, Yao Yunbiao. Curriculum Reform and Teacher Professional Development [M]. Anhui Education Press, 2007

[4] Fu Hui. An Analysis of College English Majors' Autonomous Learning Strategies Based on Internet Platform [J]. New Course Study (Mid-term), 2014 (10)

[5] Cui Wei, Chen Rui. On the Application of "Flipping Classroom” Model in English Teaching in Independent Colleges__ Taking Sifang University of Shijiazhuang Tiedao University as an Example [J]. Modern Economic Information, 2016 (05) 